\title{
Efficient reductive depolymerization of hardwood and softwood lignins with Brookhart's iridium(III) catalyst and hydrosilanes
}

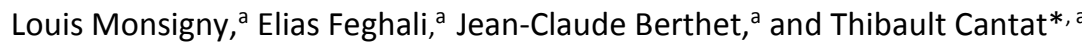 \\ Efficient catalytic reduction of lignin model molecules and reductive depolymerization of softwood and hardwood lignins is \\ presented with the iridium based Brookhart's catalyst and hydrosilanes $\mathrm{R}_{3} \mathrm{SiH}$ as reductant. This catalyst displays increased \\ stability and selectivity in comparison to the $\mathrm{B}\left(\mathrm{C}_{6} \mathrm{~F}_{5}\right)_{3} /$ hydrosilane system and it enables a convergent reductive \\ depolymerization of wood lignins to isolable mono-aromatics.
}

\section{Introduction}

Accounting for $15-30 \%$ of organic carbon in the biosphere, lignin is a prominent biopolymer, present in wood, plants, and agricultural residues. Because it derives from aromatic monolignols (Figure 1), this material can be viewed as a large and sustainable source of aromatic chemicals that could advantageously replace petrochemicals in the long run. ${ }^{1,2}$ Whereas lignin is currently burnt to supply energy in the pulp and paper industry, the chemical valorization of this biopolymer requires the selective deconstruction of its polymeric structure into a narrow range of molecules. Such endeavor remains a challenge at present due to the chemical stability and heterogeneity of lignin and the lack of robust and active catalysts as well as reaction conditions of general applicability. ${ }^{3-8}$ With a high content of $\alpha-0-4$ and $\beta-0-4$ ethereal linkages (up to $70 \%$, Fig. 1), ${ }^{9,10}$ the efficient cleavage of the $\mathrm{C}-\mathrm{O}$ bonds in lignin is a key step to promote its depolymerization and, at present, two main strategies based on oxidative or reductive conversion are being considered to obtain aromatic chemicals.

The oxidative depolymerization of lignin offers a highly efficient entry to the solubilization of lignin and a difficulty in this approach remains the isolation of pure aromatics. ${ }^{11,12}$ In contrast, mild reductive routes that would converge towards monoaromatics derivatives of the constituting monolignols (Fig. 1), by replacing $\mathrm{C}-\mathrm{O}$ bonds with $\mathrm{C}-\mathrm{H}$ bonds, are quite rare. ${ }^{13}$ Recently, Westwood et al isolated phenolic monomers of lignin through a two-step procedure involving first selective oxidation of $\mathrm{C}_{\alpha}-\mathrm{OH}$ groups and then $\mathrm{C}-\mathrm{O}$ bond reduction of $\beta-0-4$ linkages with stoichiometric amounts of zinc metal. ${ }^{14}$ De Vries, Barta et al. ${ }^{15-17}$ and Luterbacher et al. ${ }^{18}$ explored over the last years an alternative approach where lignin is first depolymerized via acidolysis, in the presence of a diol or formaldehyde to stabilize reactive electrophilic intermediates and avoid re-polymerization through $\mathrm{C}-\mathrm{C}$ bond formation. Subsequent hydrogenation enabled the formation of a narrow range of monocyclic products. In 2015, our group reported the first catalyst $\left(B\left(C_{6} F_{5}\right)_{3}\right)$ that promotes, in the presence of hydrosilanes, the direct and efficient reductive depolymerization of a variety of softwood (resinous trees) and hardwood (leaved trees) ${ }^{19,20}$ lignins into isolable monoaromatic products. $^{21}$ Depending on the wood source and the depolymerization conditions a high degree of convergence could be reached, with the formation of 1 to 4 monoaromatics. The stability of the $B\left(C_{6} F_{5}\right)_{3}$ catalyst however seemed strongly related to the presence of lignin impurities and the nature of the solvents. More stable catalysts are therefore needed to extend the potential of a direct reductive depolymerization of lignin. Brookhart's cationic iridium(III) pincer complex $[1]\left[B\left(C_{6} F_{5}\right)_{4}\right]$ is a well-known catalyst in the hydrosilylation of $\mathrm{C}-\mathrm{O}$ and $\mathrm{C}=\mathrm{O}$ bonds. ${ }^{22-26}$ Notably, Brookhart et al. have shown that $[1]\left[B\left(\mathrm{C}_{6} \mathrm{~F}_{5}\right)_{4}\right]$ could cleave the $\mathrm{C}\left(\mathrm{sp}^{3}\right)-\mathrm{O}$ bond in alkylethers to yield a silylether and an alkane. ${ }^{22}$ The similar chemical behavior of the Lewis acids $B\left(C_{6} F_{5}\right)_{3}$ and $[1]\left[B\left(C_{6} F_{5}\right)_{4}\right]^{27-29}$

led us to compare their stabilities and activities in the reduction of $\alpha-0-4$ and $\beta-0-4$ linkages, both in model molecules and lignin matrices. Here, we report the first molecular metal catalyst,

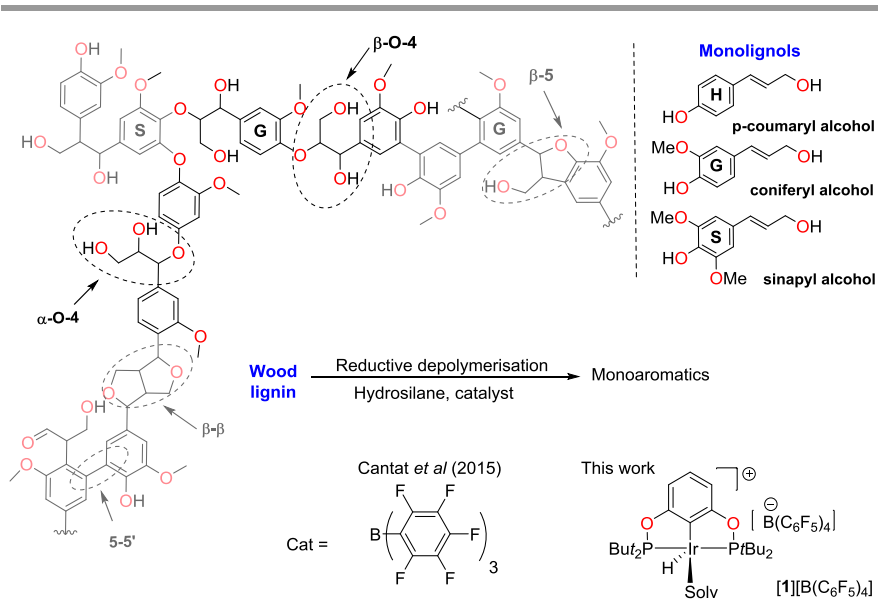

Figure 1 Convergent reductive hydrosilylation procedures for depolymerization of lignin

$[1]\left[B\left(C_{6} F_{5}\right)_{4}\right]$, that depolymerizes softwood and hardwood lignins under hydrosilylation conditions and affords the highest yields reported for isolated aromatic products under homogeneous conditions. This reaction also highlights the first successful depolymerization of a natural polymer with the Brookhart catalyst.

\section{Results and discussion}

The efficiency of $[1]\left[B\left(\mathrm{C}_{6} \mathrm{~F}_{5}\right)_{4}\right]$ in the catalytic cleavage of $\alpha-\mathrm{O}-4$ and $\beta-0-4$ linkages was first evaluated on lignin model compounds. At room temperature (RT), treatment of benzyl phenyl ether 2 in the presence of 1.2 equiv. $\mathrm{Et}_{3} \mathrm{SiH}$ and with 2 mol\% [1] $\left[\mathrm{B}\left(\mathrm{C}_{6} \mathrm{~F}_{5}\right)_{4}\right]$ effectively led, after $16 \mathrm{~h}$ in chlorobenzene, to the selective hydrosilylation of the $\mathrm{C}\left(\mathrm{sp}^{3}\right)-\mathrm{O}$ bond with formation of 4 as the major product $(92 \%)$ and toluene and phenoxysilane 3a as minor products ( $<5 \%$ yield) (Scheme 1 , Eq.1).

Notably, the $\mathrm{C}\left(\mathrm{sp}^{2}\right)-\mathrm{O}$ bond in $\mathbf{2}$ was left untouched, in line with the previous findings of the Brookhart group. ${ }^{22}$ Compound $\mathbf{4}$ is a diaryl product that likely results from a Friedel-Crafts alkylation of $3 a$ by the transient $\mathrm{PhCH}_{2}{ }^{+}$cation (formed by deoxygenation of $\mathbf{2}$ with a silylium cation). Models $\mathbf{5}$ and $\mathbf{7}$ exhibit a $\beta-0-4$ linkage with a hydroxyl group at the $\alpha$ position for $\mathbf{5 a}$ and $\mathbf{5 b}$ and two hydroxyls at the $\alpha$ and $\gamma$ positions in the 
more realistic model $\mathbf{7}$. In contrast to $\mathbf{2}$, no $\mathrm{C}-\mathrm{O}$ bond scission was observed when $\mathbf{5 a / b}$ and $\mathbf{7}$ were exposed, at RT, to $2 \mathrm{~mol} \%$ of $[1]^{+}$with excess $\mathrm{Et}_{3} \mathrm{SiH}$ ( $n>5$ equiv.) and dehydrogenative silylation of the $\mathrm{O}-\mathrm{H}$ groups was observed as the sole reaction (see ESI). Nevertheless, at $70^{\circ} \mathrm{C}$, 5 a reacted with 3 equiv. $\mathrm{Et}_{3} \mathrm{SiH}$ and 2 mol\% $[1]\left[B\left(C_{6} F_{5}\right)_{4}\right]$ to yield $3 a$ and silyether 6 in $92 \%$ yield, without recondensation (Scheme 1, Eq. 2). Similarly, the coniferyl derivative $\mathbf{5 b}$ was converted to $\mathbf{3} \mathbf{b}$ and $\mathbf{6}$ in $99 \%$ yield, when 4 equiv. $\mathrm{Et}_{3} \mathrm{SiH}$ were used, and $\mathrm{H}_{2}$ and $\mathrm{CH}_{4}$ by-products were observed by GC. Using analogous conditions, 7 was successfully converted to $\mathbf{3 a}$ and $\mathbf{8}$ (83-99\%), after hydrosilylation of the $\mathrm{O}-\mathrm{H}$ and $\mathrm{C}\left(\mathrm{sp}^{3}\right)-\mathrm{O}$ bonds (Scheme 2, Eq. $3)$. These reactions also proceeded with other silanes $\left(\mathrm{Et}_{2} \mathrm{SiH}_{2}\right.$, PMHS, TMDS...) but, due to the presence of several Si-H functionalities in these reductants, analyses of the products were complicated by the number of silylated compounds (see $\mathrm{ESI})$. Whereas the $[1]\left[\mathrm{B}\left(\mathrm{C}_{6} \mathrm{~F}_{5}\right)_{4}\right] / \mathrm{Et}_{3} \mathrm{SiH}$ system is able to reduce the $\mathrm{C}\left(\mathrm{sp}^{3}\right)-\mathrm{O}$ bond in the $\alpha-\mathrm{O}-4$ and $\mathrm{\beta}-\mathrm{O}-4$ linkages, no deoxygenation of the primary ( $\gamma$ position) and secondary ( $\alpha$ position) alcohols was noted.
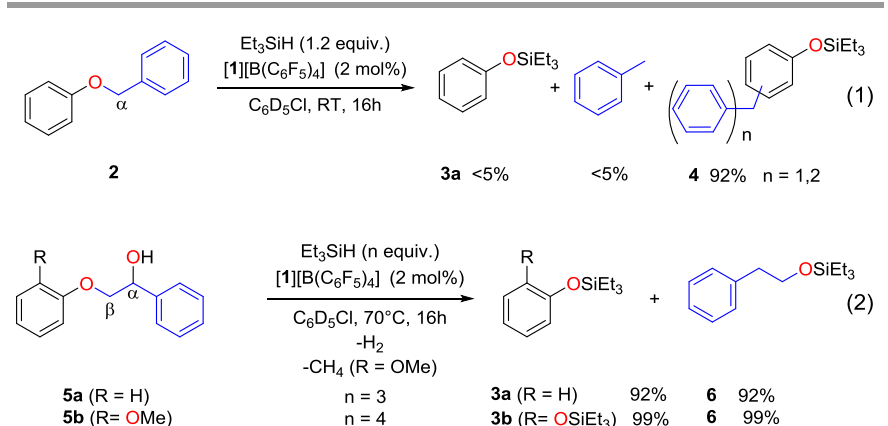

Scheme 1 Reductive cleavage of simple $\alpha-0-4$ and $\beta-0-4$ model 2 (eq. (1)) and $\mathbf{5 a}$ and $\mathbf{5 b}$ (eq. (2)) using $\mathrm{Et}_{3} \mathrm{SiH}$ and the catalyst $[\mathbf{1}]\left[\mathrm{B}\left(\mathrm{C}_{6} \mathrm{~F}_{5}\right)_{4}\right]$.
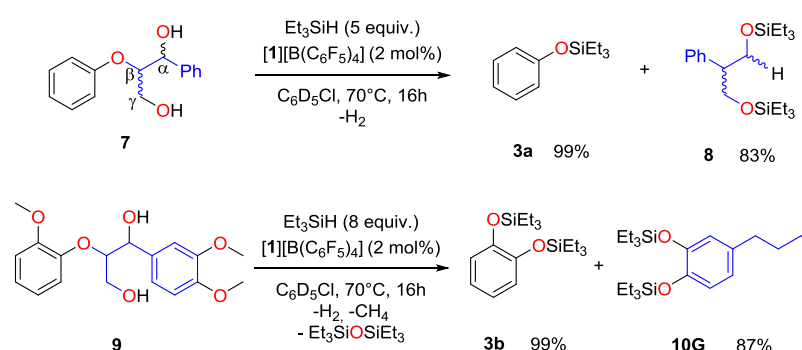

3a $99 \%$

$883 \%$

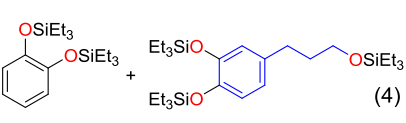

9

3b $99 \%$

$10 \mathrm{G} \quad 87 \%$

Scheme 2 Reductive cleavage of realistic $\beta-0-4$ model 7 (eq. (3)) and 9 (eq. (4)) using $\mathrm{Et}_{3} \mathrm{SiH}$ and the catalyst $[\mathbf{1}]\left[\mathrm{B}\left(\mathrm{C}_{6} \mathrm{~F}_{5}\right)_{4}\right]$.

These observations are consistent with previous results on $\mathrm{C}-\mathrm{O}$ bond hydrosilylation of ethers ${ }^{22}$ and the alcoholysis of hydrosilanes by cationic iridium complexes. ${ }^{30}$ The selective formation of $\mathbf{6}$ from $\mathbf{5 a / b}$, instead of the expected silylated 1phenylethanol $\left.\left(\mathrm{PhCH}_{(\mathrm{OSiEt}}\right) \mathrm{Me}\right)$, likely results from a semi pinacol rearrangement with migration of a phenyl group, as observed with the $\mathrm{B}\left(\mathrm{C}_{6} \mathrm{~F}_{5}\right)_{3}-\mathrm{Et}_{3} \mathrm{SiH}$ system. ${ }^{31} \mathrm{~A}$ similar rearrangement accounts for the formation of $\mathbf{8}$. The coniferyl alcohol derivative $\mathbf{9}$, which differs from $\mathbf{7}$ by the presence of additional methoxy substituents on the aromatic rings, is a more realistic structural model of lignin. ${ }^{32}$ Hydrosilylation of 9 with an excess $\mathrm{Et}_{3} \mathrm{SiH}$ (8 equiv.) and 2 mol\% [1] $\left[\mathrm{B}\left(\mathrm{C}_{6} \mathrm{~F}_{5}\right)_{4}\right]$ afforded the tris-silylated primary alcohol $10 \mathrm{G}$ ( $>80 \%$ yield), along with $\mathbf{3 b}$ (Scheme 2, Eq. 4). Further reduction of the $\mathrm{C}_{\gamma}-\mathrm{OSi}$ bond in 10G, to yield the propyl derivative $\mathrm{CH}_{3}-\left(\mathrm{CH}_{2}\right)_{2-}$
$\left(\mathrm{C}_{5} \mathrm{H}_{2}\left\{\mathrm{OSiEt}_{3}\right\}_{3}\right)$, only proceeded under harsher conditions $\left(90^{\circ} \mathrm{C}\right.$ for 5 days, see ESI). Interestingly, the formation of $10 \mathrm{G}$ shows that the reduction of $\mathbf{9}$ differs from the reduction of $\mathbf{5}$ and $\mathbf{7}$ and occurs without any semi-pinacol rearrangement, thereby exemplifying the importance of the aromatic substituents on the reactivity of lignin model compounds. To better understand this change in reactivity, DFT calculations were performed on model structures of $\mathbf{5}$ and $\mathbf{9}$ (see Scheme 3 and ESI). Upon activation of silylated $\mathbf{5}$ with the $\mathrm{R}_{3} \mathrm{Si}^{+}$cation (generated by the electrophilic activation of the hydrosilane with the Lewis acidic catalyst), the $\mathrm{C}_{\alpha}-\mathrm{O}$ bond cleavage in $\mathbf{5 a}$ is kinetically favored. Yet, the formation of the corresponding cation $\mathbf{6 a +}{ }^{\prime}$, bearing a positive charge on $C_{\alpha}$, is endergonic $(\Delta G=+4.1 \mathrm{kcal} / \mathrm{mol})$ and $5 \mathrm{a}^{+}$ rather rearranges to the more stable $6 \mathbf{a}^{+}$intermediate by semipinacol rearrangement $(\Delta G=-10.4 \mathrm{kcal} / \mathrm{mol})$. The latter cation then accumulates prior to its reduction to 6 (and 3a). In contrast, when methoxy substituents are introduced on the phenyl ring (as in 9), the stability of MeO-6a'+ increases and its formation becomes exergonic $(\Delta \mathrm{G}=-2.7 \mathrm{kcal} / \mathrm{mol})$ and kinetically favored, thereby leading to a primary silylether. This behavior directly results from the enhanced stability of a positive charge on the $C_{\alpha}$ center provided by the electron donating methoxy substituents in $\mathrm{G}$ and $\mathrm{S}$ units.

Results depicted in Eqs. 1-4 provide interesting trends for comparing the $[1]\left[B\left(C_{6} F_{5}\right)_{4}\right]$ and $B\left(C_{6} F_{5}\right)_{3}$ catalysts in the hydrosilylation of lignin models (reaction conditions: 2 mol\% catalysts, $\mathrm{Et}_{3} \mathrm{SiH}$ as reductant, $16 \mathrm{~h}$ ). The two catalysts share similar mechanistic schemes, leaving $\mathrm{C}\left(\mathrm{sp}^{2}\right)-\mathrm{O}$ bonds untouched

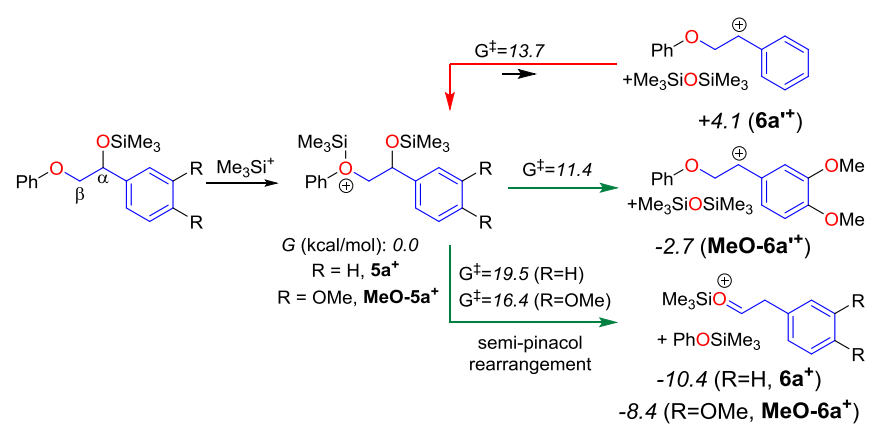

Scheme 3 Influence of methoxy substituents on the potential energy surface for $\mathrm{C}_{\alpha}-\mathrm{O}$ bond in lignin model compounds activated with silylium cations, as determined by DFT calculations (see ESI for computational details).

and promoting semi-pinacol rearrangements in $\mathbf{5}$ and $\mathbf{7}$. While $\mathrm{B}\left(\mathrm{C}_{6} \mathrm{~F}_{5}\right)_{3}$ is active at $\mathrm{RT}$, heating to $70^{\circ} \mathrm{C}$ is required for $[1]\left[B\left(C_{6} F_{5}\right)_{4}\right]$. The latter catalyst overall exhibits an enhanced chemoselectivity and it is able to reduce selectively the $\mathrm{C}_{\alpha}-\mathrm{O}$ and $\mathrm{C}_{\beta}-\mathrm{O}$ bonds in 9 with an excess hydrosilane, whereas $\mathrm{C}_{\alpha}-\mathrm{O}$, $\mathrm{C}_{\beta}-\mathrm{O}$ and $\mathrm{C}_{\gamma}-\mathrm{O}$ bond cleavages are competing with the $\mathrm{B}\left(\mathrm{C}_{6} \mathrm{~F}_{5}\right)_{3} / \mathrm{Et}_{3} \mathrm{SiH}$ system, leading to over-reduction.

Having in hand an efficient catalytic system for the reductive cleavage of $\alpha-0-4$ and $\beta-0-4$ linkages, the depolymerization of natural lignin was then attempted, with the aim to overcome the structural diversity and complexity of this biopolymer and access to narrow range of products, in a single step. Lignin, extracted from industrial pine with a Formacell process ${ }^{\dagger}$ was exposed to a chlorobenzene solution of $[1]\left[B\left(C_{6} F_{5}\right)_{4}\right]$ (25 wt\% relative to lignin weight, corresponding to ca. $3.5 \mathrm{~mol} \%$ per aromatic unit) and a slight 
excess of $\mathrm{Et}_{3} \mathrm{SiH}(273 \mathrm{wt} \%$, ca. $5 \mathrm{Si}-\mathrm{H}$ functionalities per aromatic unit). Within $24 \mathrm{~h}$ at $90^{\circ} \mathrm{C}$, the complete dissolution of the lignin matrix was observed and 10G was obtained as the sole monoaromatic product. Compound 10G was isolated in $99 \mathrm{wt} \%$ yield as colorless oil after purification by chromatography (Scheme 4). The expected diaromatic compounds (which would represent a significant amount of the hydrosilylated products $\approx 140 \mathrm{wt} \%$ for industrial pine lignin) could not be isolated because they are retained on the chromatographic column. The mass of $10 \mathrm{G}$ corresponds to a molar yield of $38 \%$ in aromatic compounds (see ESI). The formation of $10 \mathrm{G}$ demonstrates the successful transposition of the $[\mathbf{1}]\left[\mathrm{B}\left(\mathrm{C}_{6} \mathrm{~F}_{5}\right)_{4}\right] / \mathrm{Et}_{3} \mathrm{SiH}$ hydrosilylation system

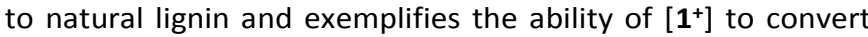
highly functional substrates.

Optimization of the depolymerization conditions, by extending the reaction time to $48 \mathrm{~h}$ in the presence of a low catalyst charge of $10 \mathrm{wt} \%$ (ca. $1.3 \mathrm{~mol} \%$ per aromatic unit) ${ }^{\ddagger}$ with $300 \mathrm{wt} \% \mathrm{Et}_{3} \mathrm{SiH}$ at $70{ }^{\circ} \mathrm{C}$ (Table 1), enabled the formation of $10 \mathrm{G}$ in $120 \mathrm{wt} \%$ yield, corresponding to a molar yield of $46 \%$.

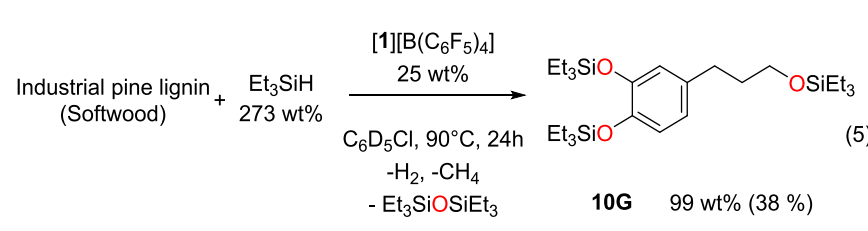

Scheme 4 Reductive depolymerization of Formacell lignin (derived from industrial pine) to $10 \mathrm{G}$, using $[1]\left[\mathrm{B}\left(\mathrm{C}_{6} \mathrm{~F}_{5}\right)_{4}\right] / \mathrm{Et}_{3} \mathrm{SiH}$.

Table 1 Optimisation of $[1]\left[B\left(\mathrm{C}_{6} \mathrm{~F}_{5}\right)_{4}\right] / \mathrm{Et}_{3} \mathrm{SiH}$ system on industrial pine lignin.

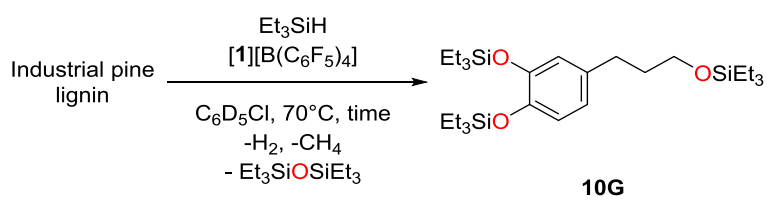

\begin{tabular}{cccccc}
\hline Entry & $\begin{array}{c}{[1]\left[\mathrm{B}\left(\mathrm{C}_{6} \mathrm{~F}_{5}\right)_{4}\right]} \\
\left(w \mathrm{wt}^{(\mathrm{a})}\right.\end{array}$ & $\begin{array}{c}\mathrm{Et}_{3} \mathrm{SiH} \\
(\mathrm{wt} \%)^{(\mathrm{a})}\end{array}$ & $\begin{array}{c}\text { Time } \\
(\mathrm{h})\end{array}$ & $\begin{array}{c}\text { 10G } \\
(\mathrm{wt} \%)^{(\mathrm{a})}\end{array}$ & Yield $^{(\mathrm{b})}$ \\
\hline 1 & 50 & 273 & 16 & $65^{(\mathrm{c})}$ & 25 \\
2 & 20 & 273 & 24 & 110 & 42 \\
3 & 20 & 300 & 24 & 120 & 46 \\
4 & 10 & 300 & 48 & 120 & 46 \\
5 & 5 & 300 & 72 & 0 & 0
\end{tabular}

(a) $w t \%=w t / w t$ of lignin ${ }^{(b)}$ The molar yield is defined as being the ratio between the isolated molar number of $\mathbf{1 0 G}(\mathrm{mol})$ and the molar number of monoaromatic units in lignin (mol) (see ESI) (c) Traces of over-reduction of $\mathbf{1 0 G}$ to the corresponding alkane are recorded. All reactions at $70^{\circ} \mathrm{C}$.

Interestingly, in presence of $5 \mathrm{wt} \% \quad[1]\left[\mathrm{B}\left(\mathrm{C}_{6} \mathrm{~F}_{5}\right)_{4}\right]$, no depolymerization products could be identified by GC-MS and NMR spectroscopies, although the lignin matrix was completely solubilized, from the hydrosilylation of the hydroxyl groups (Entry 5, Table 1).

This would suggest that a minimum quantity of catalyst is required because common impurities in lignin, such as residual carbohydrates and lipids, are known to deactivate and poison catalyst systems. ${ }^{32}$

Replacing industrial pine with other softwood varieties, namely Pacific red cedar, Lebanese cedar and Norway spruce, Formacell lignins were deconstructed to 10G, in 11, 69 and $81 \mathrm{wt} \%$ yield, respectively, with molar yields ranging 4 to $31 \%$ (Scheme 5 , Eq. 7).

As depicted in Scheme 5, the reactions are highly selective leading to $10 \mathrm{G}$ as the major monoaromatic product. The other diaromatic compounds were not detected in GC-MS because of their excessive weights. The depolymerization of hardwood lignins was carried out next. In addition to contain a greater proportion of $\beta-0-4$ cleavable linkages than softwood ${ }^{2}$, these lignins present both sinapyl (S) and coniferyl (G) residues.

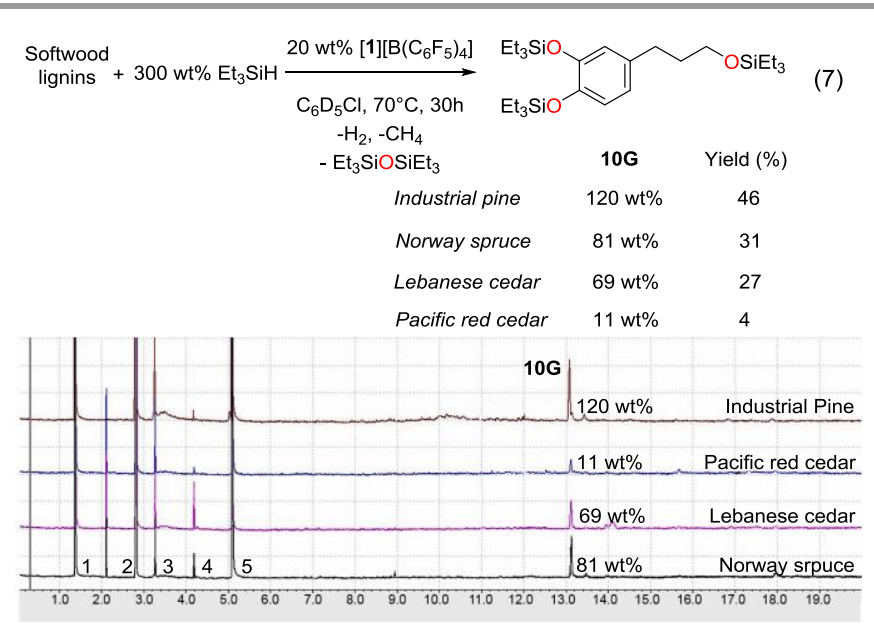

Scheme 5 Depolymerization of softwood lignins with $[1]\left[B\left(\mathrm{C}_{6} \mathrm{~F}_{5}\right)_{4}\right] / \mathrm{Et}_{3} \mathrm{SiH}$ to $10 \mathrm{G}$ (Eq. 7). GC-MS chromatograms of the crude reactional mixture for a variety of softwood lignins. 1) $\mathrm{CH}_{2} \mathrm{Cl}_{2}$ (solvent added for $\mathrm{GM}-\mathrm{MS}$ analyses), 2) $\mathrm{C}_{6} \mathrm{H}_{5} \mathrm{Cl}, 3$ ) $\left.\left.\mathrm{Et}_{3} \mathrm{SiOH}, 4\right) \mathrm{Et}_{3} \mathrm{SiH}, 5\right) \mathrm{Et}_{3} \mathrm{SiOSiEt}_{3}$

They are thus more oxidized and require forcing conditions with a larger charge of hydrosilane. As a consequence, the hydrosilylation of lignin samples obtained from black poplar, evergreen oak, hybrid plane and common beech was achieved at $70^{\circ} \mathrm{C}$ in chlorobenzene, with 20 wt\% catalyst and 364 wt\% $\mathrm{Et}_{3} \mathrm{SiH}$ (i.e. ca. 6.3 molar equivalents per aromatic unit) (Scheme 6, Eq. 8).

GC chromatograms recorded after $48 \mathrm{~h}$ showed $10 \mathrm{~S}$ and $10 \mathrm{G}$ to be the main monoaromatic products. In contrast to the resinous counterparts, they also evidenced a number of minor and undetermined side products (see ESI). For the hardwood lignins, the quantities of $\mathbf{1 0 S}$ are larger than that of $10 \mathrm{G}$, with yields varying within 80-130 wt\% and 20-42 wt\%, respectively, in line with their relative proportions in the lignin matrices (e.g. ratio 10S/10G: 70/30, see ESI). Here again, the mean molar yields depend on the wood type and are quite high ranging $36 \%$ for black poplar to $58 \%$ for evergreen oak (Eq. 8).

While the reductive depolymerization of lignin could be achieved within hours at RT when catalysed with $B\left(C_{6} F_{5}\right)_{3}$, Brookhart's catalyst appears less reactive requiring heating to $70{ }^{\circ} \mathrm{C}$. To compare precisely the two catalytic systems, depolymerization experiments of pine lignin were thus carried out with the same molar quantities $(2.9 \mu \mathrm{mol})$ of catalyst, namely $10 \mathrm{wt} \%[1]\left[\mathrm{B}\left(\mathrm{C}_{6} \mathrm{~F}_{5}\right)_{4}\right]$ and $3 \mathrm{wt} \% \mathrm{~B}\left(\mathrm{C}_{6} \mathrm{~F}_{5}\right)_{3}$.

Under these conditions, as summarized in Scheme 7, the boron catalyst proved inefficient at RT or $70^{\circ} \mathrm{C}$, both in dichloromethane and chlorobenzene, and no trace of $10 \mathrm{G}$ could be detected by GC-MS. The lack of activity of $B\left(\mathrm{C}_{6} \mathrm{~F}_{5}\right)_{3}$ certainly results from its degradation or poisoning. This also reveals the enhanced robustness of the iridium catalyst which displays a 
TON of 28 considering the molar yield of monoaromatic products with respect to the catalyst loading (see ESI).§

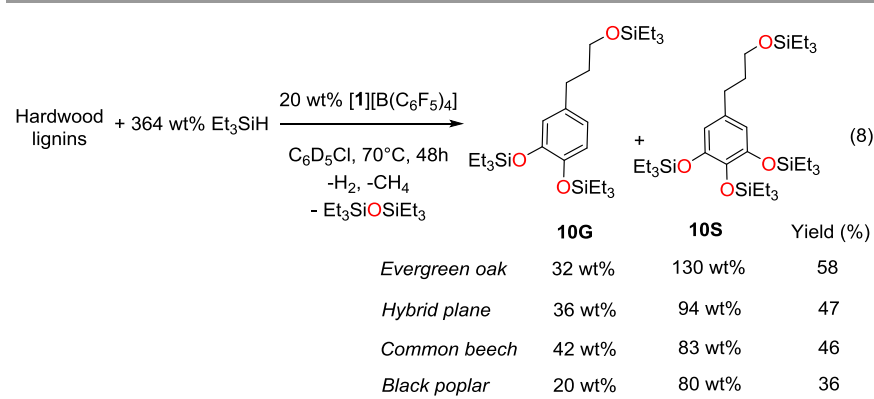

Scheme 6 Reductive depolymerization of Formacell lignin (derived from hardwood) to $10 \mathrm{G}$ and $10 \mathrm{~S}$, using $[1]\left[\mathrm{B}\left(\mathrm{C}_{6} \mathrm{~F}_{5}\right)_{4}\right] / \mathrm{Et}_{3} \mathrm{SiH}$.

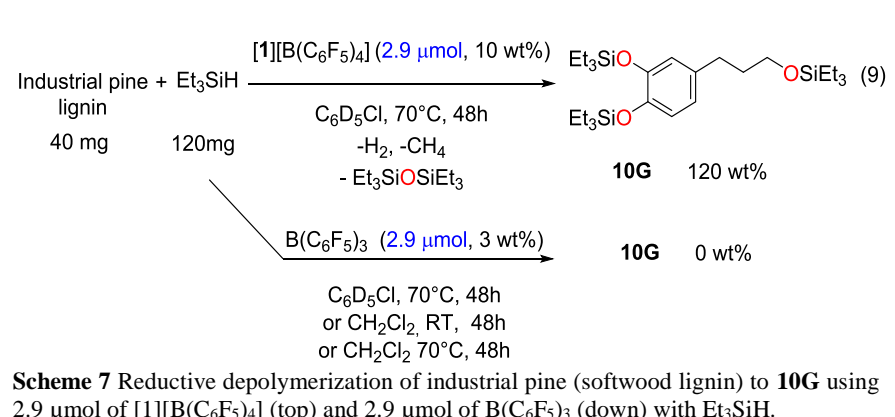

$2.9 \mu \mathrm{mol}$ of $[1]\left[\mathrm{B}\left(\mathrm{C}_{6} \mathrm{~F}_{5}\right)_{4}\right]$ (top) and $2.9 \mu \mathrm{mol}$ of $\mathrm{B}\left(\mathrm{C}_{6} \mathrm{~F}_{5}\right)_{3}$ (down) with $\mathrm{Et}_{3} \mathrm{SiH}$

Another key difference between the two catalysts $[\mathbf{1}]^{+}$and $\mathrm{B}\left(\mathrm{C}_{6} \mathrm{~F}_{5}\right)_{3}$ lies on their distinct chemoselectivity. While $10 \mathrm{G}$ and $10 \mathrm{~S}$ are obtained selectively from the treatment of softwood and hardwood lignins with [1] ${ }^{+}$and an excess hydrosilane, respectively, over-reduced derivative with the propyl chain was only obtained with the use of $\mathrm{B}\left(\mathrm{C}_{6} \mathrm{~F}_{5}\right)_{3} .{ }^{19}$

The efficiency of lignin depolymerization with $[1]\left[B\left(C_{6} F_{5}\right)_{4}\right]$ was quantified as the ratio of the experimental yield in monoaromatics products on the theoretical yield (see ESI). It is different from the molar yield because not all the interunit linkages in lignin can be reduced. This calculation required the knowledge of the mean molecular weight of Formacell lignin (determined by SEC analyses) and the content in cleavable linkages (e.g. $\beta-0-4$ content). ${ }^{21}$ The amount of $\beta-0-4$ linkages was evaluated from the HSQC NMR spectra of the lignin samples by two classical approaches, i) when quantified with respect to aromatics units or ii) when expressed as a percentage of the total side chain linkages (See details in ESI). The $\beta-0-4$ contents vary in the range of 42-48 per 100 aromatics and 65$70 \%$ of the interunit linkages in hardwood lignin (Table 2). While the former approach (i) fails and provides aberrant results (see ESI), the second approach was used, affording efficiencies in the range of 42 to $100 \%$ (Table 2). Overall, softwood and hardwood lignins exhibit similar efficiencies.

Isolation of phenolic compounds instead of the silylated species was important as the former are valuable synthons in chemical synthesis and industry. Hydrolysis of compounds $10 \mathrm{~S}$ and 10G with hydrated tetrabutyl ammonium fluoride afforded the corresponding propylhydroxycathecols 10S' and 10G' in 94 and $84 \%$ yield, respectively. 10S' and 10G' were thus isolated, respectively, in $55 \%$ molar yield from evergreen oak lignin (30 wt\%/wt lignin) and $36 \%$ molar yield from industrial pine lignin (26.5 wt\%/wt lignin) (scheme 8 ). These are the highest yields in isolated mono-aromatic compounds ever obtained from lignin under homogeneous conditions. ${ }^{7,8}$ The cost of the catalysts as well as the release of wastes (siloxanes, fluorosilanes) are however drawbacks of the present method. Current efforts are being devoted to improve the sustainability of hydrosilylation chemistry, for example through the use of silylformates. ${ }^{33}$ In addition, formic acid would be an attractive reductant in lignin depolymerization.

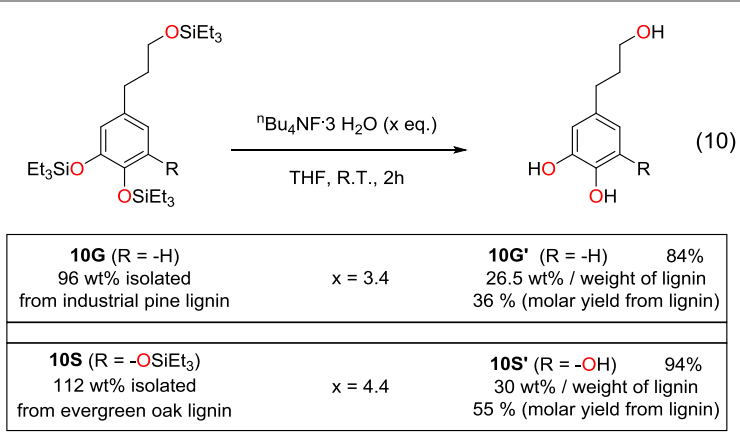

Scheme 8 Hydrolysis of the silyl ethers products with ${ }^{\mathrm{n}} \mathrm{Bu}_{4} \mathrm{NF} .3 \mathrm{H}_{2} \mathrm{O}$ from softwood and hardwood lignins

Table 2 Abundance of $\beta-04$ content in lignin samples and calculations of efficiencies of the depolymerisation within the experimental conditions: $70{ }^{\circ} \mathrm{C}$ in chlorobenzene, 30-48h, $[1]\left[\mathrm{B}\left(\mathrm{C}_{6} \mathrm{~F}_{5}\right)_{4}\right](10-20 \mathrm{wt} \%), 300-364 \mathrm{wt} \% \mathrm{Et}_{3} \mathrm{SiH}$.

\begin{tabular}{|c|c|c|c|c|c|}
\hline \multirow{2}{*}{ Lignin source } & \multirow{2}{*}{$\beta-O-4^{\prime}$ content } & \multirow{2}{*}{$\begin{array}{c}\text { Molar yield in } \\
\text { 10G or 10G + 10S } \\
(\%)\end{array}$} & $\begin{array}{c}\text { Theoretical yield } \\
\text { (\%) }\end{array}$ & $\mathrm{Eff}^{(\mathrm{c})}$ & \multirow{2}{*}{$\begin{array}{l}\text { Yield in phenolic } \\
\text { compounds } \\
\left.\text { (10G' or } \mathbf{1 0 S}^{\prime}\right)\end{array}$} \\
\hline & & & \multicolumn{2}{|c|}{$\begin{array}{c}\text { Based on relative abundance of } \\
\beta-O-4 \text { in lignin side chains }\end{array}$} & \\
\hline Industrial Pine & $63 \%^{(\mathrm{a})}(35.1)^{(\mathrm{b})}$ & $46 \%$ & $46 \%$ & $100 \%$ & $38 \%$ \\
\hline Norway Spruce & $46 \% \quad(20.2)$ & $31 \%$ & $35 \%$ & $89 \%$ & n.d. \\
\hline Lebanese Cedar & $59 \% \quad(38.9)$ & $27 \%$ & $46 \%$ & $58 \%$ & n.d. \\
\hline Pacific Red Cedar & $20 \%$ & $4 \%$ & $10 \%$ & $42 \%$ & n.d. \\
\hline Evergreen Oak & $70 \% \quad(48.1)$ & $58 \%$ & $60 \%$ & $96 \%$ & $55 \%$ \\
\hline Hybrid Plane & $65 \% \quad(42.5)$ & $47 \%$ & $60 \%$ & $79 \%$ & n.d. \\
\hline Common Beech & $65 \% \quad(43.7)$ & $46 \%$ & $60 \%$ & $77 \%$ & n.d. \\
\hline Black Poplar & $76 \% \quad(47.2)$ & $36 \%$ & $60 \%$ & $60 \%$ & n.d. \\
\hline
\end{tabular}


(a) percentage of $\beta-0-4^{\prime}$ based on the total interunit linkages determined by HSQC NMR $\left(\beta-0-4^{\prime}+\beta-\beta^{\prime}+\beta-5^{\prime}+\beta-1^{\prime}=100\right)$. (b) per 100 aromatics; (c) Efficiency is defined as being the ratio of the experimental yield of $10 \mathrm{G}$ or $10 \mathrm{G}+10 \mathrm{~S}$ (wt\%) on the theoretical yield. n.d.: not determined

\section{Conclusions}

In summary, we have reported herein the first use of the Brookhart's iridium complex as a catalyst in the reductive cleavage of lignin model molecules and softwood and hardwood lignins.

Combined with hydrosilanes, $[1]\left[B\left(\mathrm{C}_{6} \mathrm{~F}_{5}\right)_{4}\right]$ favors selective splitting of the $\mathrm{C}\left(\mathrm{sp}^{3}\right)-\mathrm{O}$ bonds in alkyl ethers and secondary silyl ether to provide silylated monoaromatic chemicals, with coniferyl $\mathbf{G}$ and sinapyl $\mathbf{S}$ residues, that can be isolated with high yields in a pure form. Although $[\mathbf{1}]\left[\mathrm{B}\left(\mathrm{C}_{6} \mathrm{~F}_{5}\right)_{4}\right]$ displays a lower catalytic activity than $\mathrm{B}\left(\mathrm{C}_{6} \mathrm{~F}_{5}\right)_{3}$, this complex exhibits a greater stability and selectivity and represent a rare example of a catalyst able to depolymerize lignin to isolable monoaromatics.

\section{Acknowledgements}

For financial support of this work, we acknowledge the CEA, CNRS, CHARMMMAT Laboratory of Excellence and the European Research Council (ERC Starting Grant Agreement n.336467). T.C. thanks the Fondation Louis D. - Institut de France for its support. We thank CINES for the allowance of computer time (Project No. c2017086494). The authors thank Dr Patrick Berthault for his assistance with NMR experiments.

\section{Notes and references}

+ We have previously reported from steric exclusion chromatography (ref. 19) that lignin obtained from the formacell organosolv process consisted in oligomers featuring a mean sequence of 5 aromatic units, with mainly $\mathbf{S}$ and $\mathbf{G}$ aromatic units (Scheme 1) for hardwood and essentially $\mathbf{G}$ units for softwood.

* $1.3 \mathrm{~mol} \%$ is found with $[1]\left[\mathrm{B}\left(\mathrm{C}_{6} \mathrm{~F}_{5}\right)_{4}\right]\left(1351 \mathrm{~g} \cdot \mathrm{mol}^{-1}\right)$ and a mean molecular weight for industrial pine lignin of $1099 \mathrm{~g} \cdot \mathrm{mol}^{-1}$.

$\S$ If one considers that the production of 10G from softwood lignin requires $6 \mathrm{C}-\mathrm{O}$ and $\mathrm{O}-\mathrm{H}$ bond silylation events, then the TON is 170 per aromatic units (see ESI).

\section{Uncategorized References}

1. D. S. Argyropoulos and S. B. Menachem, in Biopolymers from Renewable Resources, ed. D. L. Kaplan, Springer Berlin Heidelberg, Berlin, Heidelberg, 1998, DOI: 10.1007/978-3662-03680-8_12, pp. 292-322.

2. F. G. Calvo-Flores, J. A. Dobado, J. Isac-García and F. J. Martín-MartíNez, in Lignin and Lignans as Renewable Raw Materials, John Wiley \& Sons, Ltd, 2015, DOI: 10.1002/9781118682784.ch2, pp. 9-48.

3. J.-P. Lange, Angew. Chem. Int. Ed., 2015, 54, 13186-13197.

4. B. M. Upton and A. M. Kasko, Chem. Rev., 2016, 116, 22752306.
5. P. J. Deuss and K. Barta, Coord. Chem. Rev., 2016, 306, 510532.

6. S. Van den Bosch, W. Schutyser, R. Vanholme, T. Driessen, S. F. Koelewijn, T. Renders, B. De Meester, W. J. J. Huijgen, W. Dehaen, C. M. Courtin, B. Lagrain, W. Boerjan and B. F. Sels, Energy Environ. Sci., 2015, 8, 1748-1763.

7. W. Schutyser, T. Renders, S. Van den Bosch, S. F. Koelewijn, G. T. Beckham and B. F. Sels, Chem. Soc. Rev., 2018, 47, 852-908.

8. Z. Sun, B. Fridrich, A. de Santi, S. Elangovan and K. Barta, Chem. Rev., 2018, 118, 614-678.

9. M. P. Pandey and C. S. Kim, Chem. Eng. Technol., 2011, 34, 29-41.

10. Z. Strassberger, S. Tanase and G. Rothenberg, RSC Advances, 2014, 4, 25310-25318.

11. J. Zakzeski, P. C. Bruijnincx, A. L. Jongerius and B. M. Weckhuysen, Chemical reviews, 2010, 110, 3552-3599.

12. C. $\mathrm{Xu}, \mathrm{R}$. A. Arancon, J. Labidi and R. Luque, Chemical Society reviews, 2014, 43, 7485-7500.

13. M. V. Galkin and J. S. M. Samec, ChemSusChem, 2016, 9, 1544-1558.

14. C. S. Lancefield, O. S. Ojo, F. Tran and N. J. Westwood, Angewandte Chemie, 2015, 54, 258-262.

15. P. J. Deuss, C. S. Lancefield, A. Narani, J. G. de Vries, N. J. Westwood and K. Barta, Green Chemistry, 2017, 19, 27742782.

16. P. J. Deuss, M. Scott, F. Tran, N. J. Westwood, J. G. de Vries and K. Barta, J. Am. Chem. Soc., 2015, 137, 7456-7467.

17. P. J. Deuss, C. W. Lahive, C. S. Lancefield, N. J. Westwood, P. C. Kamer, K. Barta and J. G. de Vries, ChemSusChem, 2016, 9, 2974-2981.

18. L. Shuai, M. T. Amiri, Y. M. Questell-Santiago, F. Heroguel, Y. Li, H. Kim, R. Meilan, C. Chapple, J. Ralph and J. S. Luterbacher, Science, 2016, 354, 329-333.

19. M. D. Karkas, B. S. Matsuura, T. M. Monos, G. Magallanes and C. R. J. Stephenson, Org. Biomol. Chem., 2016, 14, 1853-1914.

20. A. J. Ragauskas, G. T. Beckham, M. J. Biddy, R. Chandra, F. Chen, M. F. Davis, B. H. Davison, R. A. Dixon, P. Gilna, M. Keller, P. Langan, A. K. Naskar, J. N. Saddler, T. J. Tschaplinski, G. A. Tuskan and C. E. Wyman, Science, 2014, 344.

21. E. Feghali, G. Carrot, P. Thuery, C. Genre and T. Cantat, Energy Environ. Sci., 2015, 8, 2734-2743.

22. J. Yang, P. S. White and M. Brookhart, J. Am. Chem. Soc, 2008, 130, 17509-17518.

23. J. Yang, P. S. White, C. K. Schauer and M. Brookhart, Angewandte Chemie, 2008, 47, 4141-4143.

24. S. Park and M. Brookhart, Organometallics, 2010, 29, 60576064.

25. S. Park and M. Brookhart, Chem. Commun., 2011, 47, 36433645.

26. S. Park, D. Bezier and M. Brookhart, J. Am. Chem. Soc, 2012, 134, 11404-11407.

27. T. Robert and M. Oestreich, Angew. Chem. Int. Ed., 2013, 52, 5216-5218.

28. M. P. McLaughlin, L. L. Adduci, J. J. Becker and M. R. Gagne, J. Am. Chem. Soc, 2013, 135, 1225-1227.

29. L. L. Adduci, M. P. McLaughlin, T. A. Bender, J. J. Becker and M. R. Gagne, Angew. Chem. Int. Ed., 2014, 53, 1646-1649. 
30. L. D. Field, B. A. Messerle, M. Rehr, L. P. Soler and T. W. Hambley, Organometallics, 2003, 22, 2387-2395.

31. E. Feghali and T. Cantat, Chem. Commun., 2014, 50, 862865.

32. R. Rinaldi, R. Jastrzebski, M. T. Clough, J. Ralph, M. Kennema, P. C. A. Bruijnincx and B. M. Weckhuysen, Angew. Chem. Int. Ed., 2016, 55, 8164-8215.

33. C. Chauvier, P. Thuery and T. Cantat, Angewandte Chemie, 2016, 55, 14096-14100. 